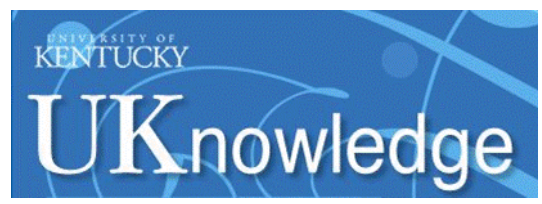

University of Kentucky

UKnowledge

7-7-2004

\title{
Social Support Protects against the Negative Effects of Partner Violence on Mental Health
}

\author{
Ann L. Coker \\ University of South Carolina - Columbia, ann.coker@uky.edu \\ Paige H. Smith \\ University of North Carolina at Greensboro, phsmith@uncg.edu \\ Martie P. Thompson \\ Clemson University, mpthomp@clemson.edu \\ Robert E. McKeown \\ University of South Carolina, rmckeown@sc.edu \\ Lesa Bethea \\ University of South Carolina - Columbia
}

See next page for additional authors

Follow this and additional works at: https://uknowledge.uky.edu/crvaw_facpub

Part of the Mental and Social Health Commons, Psychiatry and Psychology Commons, Public Health Commons, Social Work Commons, and the Sociology Commons

Right click to open a feedback form in a new tab to let us know how this document benefits you.

\section{Repository Citation}

Coker, Ann L.; Smith, Paige H.; Thompson, Martie P.; McKeown, Robert E.; Bethea, Lesa; and Davis, Keith E., "Social Support Protects against the Negative Effects of Partner Violence on Mental Health" (2004). CRVAW Faculty Journal Articles. 113.

https://uknowledge.uky.edu/crvaw_facpub/113

This Article is brought to you for free and open access by the Center for Research on Violence Against Women at UKnowledge. It has been accepted for inclusion in CRVAW Faculty Journal Articles by an authorized administrator of UKnowledge. For more information, please contact UKnowledge@lsv.uky.edu. 
Social Support Protects against the Negative Effects of Partner Violence on Mental Health

\author{
Digital Object Identifier (DOI) \\ http://dx.doi.org/10.1089/15246090260137644
}

\title{
Notes/Citation Information
}

Published in Journal of Women's Health \& Gender-Based Medicine, v. 11, no. 5, p. 465-476.

This is a copy of an article published in the Journal of Women's Health \& Gender-Based Medicine @ 2005 Mary Ann Liebert, Inc.; Journal of Women's Health \& Gender-Based Medicine is available online at:

http://online.liebertpub.com/loi/jwh.1

Dr. Ann Coker had not been a faculty member of the University of Kentucky at the time of publication.

\section{Authors}

Ann L. Coker, Paige H. Smith, Martie P. Thompson, Robert E. McKeown, Lesa Bethea, and Keith E. Davis 


\title{
Social Support Protects against the Negative Effects of Partner Violence on Mental Health
}

\author{
ANN L. COKER, Ph.D., ${ }^{1}$ PAIGE H. SMITH, Ph.D., M.S.P.H., ${ }^{2}$ \\ MARTIE P. THOMPSON, Ph.D., ${ }^{3}$ ROBERT E. McKEOWN, Ph.D., ${ }^{1}$ \\ LESA BETHEA, M.D., ${ }^{4}$ and KEITH E. DAVIS, Ph.D. ${ }^{5}$
}

\begin{abstract}
Objectives: Social support for abused women may reduce the impact of abuse on mental health, yet few studies have addressed this issue. We wish to determine associations between intimate partner violence (IPV) and mental health outcomes and to assess the protective role of abuse disclosure and support on mental health among abused women.

Methods: A cross-sectional survey was conducted of 1152 women, ages 18-65, recruited from family practice clinics from 1997 through 1999. They were screened for IPV during a brief inclinic interview, and physical and mental health status was assessed in a follow-up interview.

Results: IPV, defined as sexual, physical, or psychological abuse, was associated with poor perceived mental and physical health, substance abuse, symptoms of posttraumatic stress disorder (PTSD), current depression, anxiety, and suicide ideation/actions. Among women experiencing IPV and controlling for IPV frequency, higher social support scores were associated with a significantly reduced risk of poor perceived mental health (adjusted relative risk $[a R R] 0.5,95 \%$ confidence interval $[C I] 0.3,0.6)$ and physical health $(a R R 0.6,95 \% \mathrm{CI} 0.5,0.8)$, anxiety (aRR 0.3, 95\% CI 0.2, 0.4), current depression ( $a R R 0.6,95 \%$ CI $0.5,0.8)$, PTSD symptoms (aRR 0.5, 95\% CI 0.4, 0.8), and suicide attempts $(a R R 0.6,95 \%$ CI $0.4,0.9)$.

Conclusions: Healthcare providers can be instrumental in identifying IPV and helping women develop skills, resources, and support networks to address IPV. Physicians, family, or friends may provide needed social support.

\section{INTRODUCTION}

$\mathbf{P}$ HYSiCAl intimate PARTNER VIOlENCE (IPV) is now seen as a public health problem. The prevalence and incidence of this violence have been well documented in both clinic-based ${ }^{1-6}$ and

population-based $^{7-13}$ studies. IPV is linked to physical injuries, ${ }^{14,15}$ to poor mental health, ${ }^{16}$ including depression, anxiety, posttraumatic stress disorder (PTSD), and suicide ideation and actions; and to a wide range of adverse physical health outcomes. ${ }^{16-20}$ As documented in the first

\footnotetext{
${ }^{1}$ Department of Epidemiology and Biostatistics, University of South Carolina, School of Public Health, Columbia, South Carolina.

${ }^{2}$ Department of Public Health Education, University of North Carolina at Greensboro, North Carolina.

${ }^{3}$ Department of Public Health Science, Clemson University, Clemson, South Carolina.

${ }^{4}$ Department of Family and Preventive Medicine, University of South Carolina, Columbia, South Carolina.

${ }^{5}$ Department of Psychology, University of South Carolina, Columbia, South Carolina.

This work was funded by R49 CCR412752 of the CDC National Center for Injury Prevention and Control and the Disabilities Prevention Program of the National Center for Environmental Health.
} 
Surgeon General's report on mental health, ${ }^{21}$ mental disorders are an important contributor to morbidity and mortality in the United States. An emerging literature suggests that psychological battering and emotional abuse, as well as physical assault,, 22 have physical and mental health impact. Little epidemiological research has addressed this association between psychological battering and women's mental health. ${ }^{13}$

Further, little research has addressed protective factors that may reduce the risk of poor mental health outcomes for abused women. The adverse outcomes include depression, anxiety, PTSD, substance abuse, and suicide ideation and action. One potential factor that may protect abused women from experiencing adverse mental health outcomes is social support. Women who suffer partner abuse may be in particular need of social support, for several reasons. Abused women may not disclose abuse or seek social support because they may feel stigmatized if others know of their abuse, they may see violence in the home as a private matter, or they may fear retaliation from their partners if they disclose the abuse. ${ }^{23,24}$ Even if abused women seek social support, they may not receive the support they need because potential support providers may blame the victim or feel uncomfortable discussing this sensitive topic. Because the abuse may be chronic, abused women over time may deplete the emotional and material resources of providers. ${ }^{25}$ Consistent with these notions, Arias $^{26}$ argues that social support may moderate an association between IPV and a range of mental health outcomes, including depressive symptoms and alcohol abuse. In a case-control study of suicide attempters and nonattempters, Kaslow et al. ${ }^{27}$ found that social support did moderate the impact of IPV on suicide. Additional research is needed to address this important issue across the spectrum of mental health outcomes and the range of IPV, including physical assaults, battering, and emotional abuse. If women experiencing IPV have extensive social networks and if social resources are supportive when they learn about IPV, the potentially devastating impact of IPV may be lessened.

This is one of the first clinical studies that screened for physical assault, sexual assault, psychological battering, and emotional abuse and linked these IPV types with mental health outcomes. We add to the emerging literature in ex- ploring the role of and satisfaction with social networks in reducing the risk of these same mental health outcomes among abused women.

\section{MATERIALS AND METHODS}

\section{Data collection}

In this cross-sectional study, trained recruiters approached and interviewed 1152 women seeking medical care in two university-associated family practice clinics from February 1997 through January 1999. Eligible subjects were women, aged 18-65, insured either by Medicaid or a managed care provider. Study participation included a 5-10-minute in-clinic interview to screen for male partner violence and a 30-45minute telephone interview to assess the woman's medical history and current health status. We used computer-assisted interviewing for both in-clinic and telephone interviews to reduce errors and rapidly provide scale scores for IPV measures. In-clinic interviewers were women graduate students who received extensive training in asking these sensitive questions, active listening, and providing women with community resources. A team of four women interviewers employed by the USC survey research laboratory conducted the telephone interviews and provided community resources as needed. Women were reimbursed for their time in completing these interviews. Women currently in abusive relationships were counseled by recruiters and referred to local services for victims. For safety reasons, women currently in violent relationships were given the option to complete this longer interview in the clinic; $6.8 \%(n=98)$ of all followup interviews were conducted in the clinics. The University of South Carolina Institutional Review Board approved this project, and all women signed consent forms. Although we recognize that same-sex partner violence exists, the focus of this project was male partner violence directed against women.

\section{Measures of IPV}

We characterized IPV by (1) the timing of the violence (in a past or recent intimate relationship), (2) the type of violence (physical assault, sexual assault, battering, or emotional abuse), and (3) the frequency of the violence. We began 
by asking women whether they were currently in an intimate relationship with a man. If not, we asked her to think about her most recent relationship. We then asked about partner violence in any past relationship. We report here on lifetime IPV victimization by a current/recent partner or with any past male partner. The instrumentation methods for the study appear elsewhere. ${ }^{5}$ We provide a brief overview here.

Physical and sexual IPV. We used a modified version of the Index of Spouse Abuse-Physical $(\text { ISA-P })^{28}$ to measure the severity of physical and sexual violence inflicted by her current or most recent male partner (Cronbach's $\alpha=0.91$ ). We developed subscales of the ISA-P to separately assess physical and sexual IPV. We used the recommended weighted scale score and cut points. ${ }^{29}$ We assessed physical partner violence in a past relationship using a modification of the widely used Abuse Assessment Screen (AAS). ${ }^{30}$ Our modification was to ask specifically about physical violence ("Did your male partner hit, kick, or otherwise physically hurt you?") and forced sexual activity ("Did a male partner ever force you to have sexual activities against your will?") by a male intimate partner.

Psychological IPV. We used the Women's Experience with Battering (WEB) Scale (Cronbach's $\alpha$ $=0.95$ ) to assess battering by a current or most recent male partner. ${ }^{31-33}$ Respondents were asked to indicate their level of agreement or disagreement, using a 6-point Likert scale, with items such as, "He makes me feel unsafe in my own home," "I feel like he keeps me prisoner," "I feel owned and controlled by him," and "He has a look that goes straight through me and terrifies me." For these analyses, women were classified as psychologically battered if they scored above 20 on the WEB Scale and did not concurrently experience physical or sexual IPV. We used the AAS to assess perceived emotional abuse ("Did you ever feel emotionally or psychologically abused?") by an intimate male partner in any past relationship. Those reporting emotional abuse without concurrent physical or sexual IPV were defined as experiencing psychological IPV in the past.

Because there is considerable overlap among IPV types (physical, sexual, and psychological), we have constructed mutually exclusive hierarchical categories of lifetime IPV experience as fol- lows: (1) IPV-sexual, defined as forced sexual intercourse by an intimate partner with or without concurrent physical IPV or psychological IPV, (2) IPV-physical, defined as physical partner violence without concurrent sexual IPV; psychological abuse may also be present, and (3) IPVpsychological, defined as either current psychological battering or past emotional abuse without physical or sexual violence. The comparison group for these IPV categories was women never experiencing any type of IPV. The majority (88\%) of women who experienced physical or sexual violence also reported psychological IPV. O'Leary ${ }^{34}$ and others argue that psychological or emotional abuse alone has as detrimental an impact on mental health as does physical partner violence. Using our IPV categories, we can address the impact of lifetime sexual, physical, and psychological abuse on mental health.

\section{Demographics}

We collected the following demographic characteristics: woman's current marital status, age, race/ethnicity, education, number of household members, employment status, whether the respondent's father was either emotionally or physically abusive toward her mother, and the current male partner's age, race/ethnicity, employment status, and whether she perceives him to have a drinking or drug problem. Given the sensitive nature of the screening questions and limited interview time, we did not assess childhood physical or sexual abuse.

\section{Mental health assessment}

We assessed current mental and physical health status in the 45-minute follow-up questionnaire. Measures included the Drug Abuse Screening Test (DAST) ${ }^{35}$ (Cronbach's $\alpha=0.76$ ), the TWEAK ${ }^{36}$ to measure alcohol abuse (Cronbach's $\alpha=0.71$ ), an injury frequency and severity scale specific to partner violence (Cronbach's $\alpha=0.76$ ), the Spielberger State-Trait Personality Inventory ${ }^{37}$ to measure anxiety (Cronbach's $\alpha=$ 0.77), the Center for Epidemiologic Studies Depression (CES-D) Scale $^{38}$ to measure depressive symptoms in the past 2 weeks (Cronbach's $\alpha=$ 0.79), and DSM-IV criteria to assess for PTSD. ${ }^{39}$ We used a modification of the National Health Interview Survey ${ }^{40}$ to measure a range of specific health outcomes, including having a problem 
with depression or anxiety that required treatment. We asked the age at first experiencing these health outcomes to place the exposure in the appropriate time frame, age at first IPV experience, and subsequent development of the health outcome of interest. We assessed current self-perceived mental and physical health with the following standard question: "Compared to others your own age, do you consider your current mental/physical health to be excellent, very good, good, fair, or poor?"

\section{Social support and help-seeking measures}

We assessed social support and source of support (friend, family, and partner), response to abuse disclosure, seeking professional mental healthcare, and religiosity as potential protective factors against adverse mental health outcomes among abused women.

Social support was measured using the Social Support Questionnaire-Short Form ${ }^{41}(\alpha=0.90$ for the 5-item scale). This scale measures the woman's perception of whether there is someone she can count on to (1) "help me feel better when I am under stress," (2) "accept me totally, including both my worst and best points," (3) "care about me, regardless of what is happening to me," (4) "help me feel better when I am feeling down in the dumps," and (5) "console me when I am upset." We dichotomized the 5-item scale (range 5-25), with a high score $>20$ indicating that the women always or most of the time had someone they could count on (high social support). This cut point was selected as one standard deviation (SD) below the median score among nonabused women.

Source of support was assessed using the following question repeated for each of three sets of relationship networks: "How frequently to you receive support from" (1) "friends or co-workers," (2) "family members," and (3) "your current male partner?" The 5 response options ranged from "never" (code 1) to "always" (code 5) $(\alpha=$ 0.67 for the 3 -item score). We created a dichotomous indicator variable for consistent support based on a response that the person was always supported by the following three categories: friends, family members, and current nonabusive male partner. We did not define support for women; they are applying their own definition.

Although social support and the sources of support are highly correlated $(\beta$ coefficient $=$
0.503 for the full scale scores regressing social support on the sources of support, $p<0.001$ ), the source of support measures support received in specific relationship categories. This is important, as we can identify those social networks that may be most important for abused women to buffer the effect of abuse on health.

We measured disclosure with the following question: "How often did you talk to other people, like friends, family members, clergy, police, hairdressers, a doctor or nurse, about the problems in your relationships with an abusive partner?" We probed specifically about whether women talked to someone about violence in the relationship. Frequency options ranged from "never" to "more than 20 times." We measured support for disclosure among those disclosing abuse, using the following seven question sets: "In general, when you talked with someone, how often was their response, (1) to offer emotional support, (2) to advise you to leave the relationship, (3) to advise you to stay in the relationship [reverse code], (4) to blame you or say you deserved the abuse [reverse code], (5) to blame your partner, (6) to offer help, including a place to stay or financial assistance, and (7) to continue to spend time or stay friends with your abusive partner [reverse code]?" Response options ranged from "never" to "often." The Cronbach's $\alpha$ for this 7-item scale among abused women who disclosed abuse was 0.67 . We also created a dichotomized variable using the combined disclosure support score. Those indicating no disclosure or little support for disclosure (score of $\leq 5$ of 7) were coded as receiving little disclosure support, and those who consistently received support (score of $>5$ of 7 questions answered as "often" supportive) were coded as receiving support for disclosure. This cut point was based on a median split for the 7 items.

We asked women reporting IPV whether they had seen a mental health therapist or counselor or had attended support groups, as an indicator of help seeking for IPV. Because we have crosssectional data, we do not know whether women with significant mental disorders (e.g., PTSD and suicide attempts) were more likely to have sought professional help or whether professional help increased the risk of these disorders, but we believe the former is more probable.

We modified the Gorsuch and McPherson religiosity index ${ }^{42,43}$ to include the following two items: (1) "What religion or spirituality offers 
most is comfort in times of trouble and sorrow." (2) "Your whole approach to life is based on your religion." We dichotomized the responses to categorize those strongly agreeing to either of the two questions.

\section{Response rates}

Eleven percent of 1580 women approached for participation $(n=174)$ refused. Refusers were significantly more likely to be insured by Medicaid $(32 \%)$ than were responders $(25 \%)$. We have no additional demographic data with which to characterize refusers relative to responders. Three percent of those recruited had never had an intimate relationship (42 of 1406) and were, thus, ineligible, and $14.1 \%$ did not complete the health assessment interview (192 of 1364) or had missing data on several response variables (20 of 1364). Thus, 1152 women were included in these analyses (73\% response rate). Women not completing the health assessment interview $(n=192)$ were younger and significantly more likely to currently be in a violent relationship $(R R=2.6$; $p=0.03)$ than were women completing the health assessment.

\section{Statistical analyses}

We provide the demographic correlates of IPV experience by three IPV types (sexual, physical, and psychological) in Table 1. Because logistic regression overestimates the relative risk $(R R)$ when outcomes are common, as is true for the mental health outcomes assessed here, we used stratified analyses to directly estimate $R R$ for associations between each mental health outcome and the three IPV types, adjusting for age, race, and insurance status. Three dummy variables were used to hierarchically define IPV by typesexual, physical, and psychological IPV. The referent group for both IPV indicator variables was those never experiencing IPV. We additionally included a variable indicating whether the father was physically or emotionally abusive toward the mother because it has been shown to be related to mental health outcomes. Chi-square analyses were used to evaluate demographic differences in IPV experience (Table 1).

We conducted a subanalysis among those ever experiencing IPV to assess the effect of seeking professional mental healthcare, a supportive response to abuse disclosure, social support, source of support, and religiosity. In these analyses, we also adjusted for the frequency and severity of IPV (Tables 3 and 4).

\section{RESULTS}

In this primary care population, $53.9 \%$ of 1152 screened reported some type of IPV; $41.8 \%$ reported physical assaults, $21.4 \%$ reported sexual assaults, and $12.1 \%$ reported current psychological battering or past emotional abuse without physical or sexual assaults.

The following demographic characteristics (Table 1) were associated with sexual IPV: increasing age, Medicaid insurance, being currently unemployed, having a father who was abusive toward the woman's mother, having a current partner with a substance abuse problem, having less than a graduate school education, and not being married. These same factors were also associated with experiencing physical IPV exclusive of sexual IPV, except increasing age and being unemployed. Only white race, partner substance abuse, and being currently married were associated with psychological IPV.

Table 2 presents the prevalence of the health or behavioral outcomes in the population and the $R R$ estimates for the three IPV categories and each mental health outcome. IPV, independent of type, was associated with self-perceived mental and physical health, cigarette smoking, anxiety, depression, and suicide ideation and action. Although not associated with psychological IPV, drug and alcohol abuse were associated with sexual and physical IPV, as was having a higher PTSD symptom score. In general, the associations were stronger for these mental health outcomes for women experiencing sexual IPV than for physical IPV without sexual IPV or psychological IPV alone.

We next assessed whether help seeking and social support might reduce the risk of these adverse mental health outcomes among abused women while controlling for IPV frequency and severity, age, race, and insurance status. Table 3 presents the $a R R$ estimates for mental health help seeking, support for IPV disclosure, social support, and each measure of current mental health. The mental health help-seeking questions were asked only of women reporting recent physical or sexual partner violence $(n=252)$.

Among this subset of abused women, 38\% reported help seeking; they have talked with a men- 
Table 1. Demographic Characteristics of Women Screened for IPV $(n=1152)$ by IPV Type

\begin{tabular}{|c|c|c|c|c|}
\hline \multirow[b]{2}{*}{ Characteristic strata } & \multicolumn{4}{|c|}{$\%$ of women within strata experiencing IPV, by type } \\
\hline & $\begin{array}{l}\text { Number (\%) of } \\
\text { women by strata }\end{array}$ & $\begin{array}{l}\text { Sexual IPV } \\
\mathrm{n}=260\end{array}$ & $\begin{array}{l}\text { Physical, no } \\
\text { sexual IPV } \\
\mathrm{n}=225\end{array}$ & $\begin{array}{c}\text { Psychological IPV, no } \\
\text { physical/sexual IPV } \\
\mathrm{n}=136\end{array}$ \\
\hline \multicolumn{5}{|l|}{ Age (years) } \\
\hline $18-29$ (referent) & $324(28.2)$ & 14.8 & 21.5 & 12.9 \\
\hline $30-39$ & $320(27.7)$ & $26.6^{* *}$ & 17.5 & 10.6 \\
\hline $40-49$ & $312(27.1)$ & $24.6^{* *}$ & 21.1 & 13.7 \\
\hline $50+$ & $196(17.0)$ & $26.5^{* *}$ & 17.4 & 8.7 \\
\hline \multicolumn{5}{|l|}{ Race } \\
\hline African American & $715(62.1)$ & 23.4 & 20.6 & 10.0 \\
\hline White (referent) & $437(37.9)$ & 21.5 & 17.9 & $14.7^{*}$ \\
\hline \multicolumn{5}{|l|}{ Insurance } \\
\hline Medicaid & $255(22.1)$ & $31.4^{*}$ & $26.7^{* *}$ & 8.6 \\
\hline Managed care (referent) & $897(77.9)$ & 20.2 & 17.6 & 12.7 \\
\hline \multicolumn{5}{|l|}{ Current employment status } \\
\hline Unemployed & $129(11.2)$ & $36.4^{* *}$ & 20.9 & 5.4 \\
\hline Employed (referent) & $1023(88.8)$ & 39.5 & 21.0 & 12.6 \\
\hline \multicolumn{5}{|l|}{ Father abusive toward mother } \\
\hline Yes & $336(29.1)$ & $34.8^{* *}$ & $24.4^{* *}$ & 10.7 \\
\hline No (referent) & $816(69.9)$ & 17.8 & 17.5 & 12.2 \\
\hline \multicolumn{5}{|c|}{ Current partner has substance abuse problem } \\
\hline Yes 1 & $251(21.8)$ & $40.2^{* *}$ & $22.7^{* * *}$ & $11.6^{*}$ \\
\hline No (referent) & $901(78.2)$ & 17.9 & 18.7 & 11.9 \\
\hline \multicolumn{5}{|l|}{ Education level } \\
\hline$<$ High school & $133(11.5)$ & $38.4^{* *}$ & $20.3^{* *}$ & 6.0 \\
\hline High school graduate & $244(21.3)$ & 19.3 & 19.7 & 9.0 \\
\hline Some college & $398(34.5)$ & $24.6^{* *}$ & $21.6^{* *}$ & 12.3 \\
\hline Undergraduate degree & $253(22.0)$ & 18.9 & 19.7 & 13.8 \\
\hline Some graduate school (referent) & $124(10.7)$ & 14.5 & 11.3 & 17.7 \\
\hline \multicolumn{5}{|l|}{ Current marital status } \\
\hline Divorced or separated & $244(21.2)$ & $36.1^{* *}$ & $26.2^{* *}$ & $13.9^{* *}$ \\
\hline Single living with partner & $97(8.4)$ & $23.7^{* *}$ & $28.9^{* *}$ & $16.5^{* *}$ \\
\hline Single not living with partner & $305(26.5)$ & $20.9^{*}$ & $19.3^{*}$ & $13.4^{*}$ \\
\hline Widowed & $50(4.3)$ & $18.0^{* *}$ & $24.0^{* * *}$ & $4.0^{*}$ \\
\hline Married (referent) & $456(39.6)$ & 17.1 & 13.6 & 9.4 \\
\hline
\end{tabular}

${ }^{a}$ Hierarchical IPV categories: sexual IPV with or without physical or psychological IPV, physical IPV but not sexual IPV with or without psychological IPV, psychological IPV alone.

${ }^{*} p=0.01-0.05$.

${ }_{* *}^{* *}<0.01$

tal health therapist or counselor or attended a support group. Those seeking professional mental healthcare were significantly more likely to (1) use illegal drugs, (2) have higher PTSD symptom scores, (3) have higher anxiety scores, and (4) have ever attempted suicide.

We next addressed what proportion of all abused women disclosed the abuse to someone (e.g., friends, family members, clergy, police, a hairdresser, or a doctor or nurse); $31 \%$ never talked to anyone about the abuse, $17 \%$ talked to someone once or twice, $20 \%$ talked to someone three to ten times, and $32 \%$ talked to someone more than ten times. The majority $(82 \%)$ of those disclosing abuse reported that the persons to whom they disclosed the abuse were supportive. Disclosing abuse was not associated with a significant reduction in risk of any of the range of adverse mental health outcomes (data not shown). However, if abused women disclosed the abuse and that person's reaction to the disclosure was consistently supportive, these women were at a reduced risk of suicide ideation and actions (Table 3).

Abused women with higher social support, measured using the Social Support Questionnaire-Short Form, were significantly less likely to report current poor mental and physical health, 
Table 2. IPV by Type and Mental Health Outcomes

\begin{tabular}{|c|c|c|c|c|}
\hline \multirow[b]{2}{*}{ Mental health (MH) outcome } & \multirow[b]{2}{*}{$\begin{array}{c}\text { Prevalence } \\
\text { of outcomes } \\
\text { all women } \\
(\mathrm{n}=1152)(\%)\end{array}$} & \multicolumn{3}{|c|}{ Estimate for ever experiencing IPV, by type ${ }^{a}$} \\
\hline & & $\begin{array}{l}\text { Sexual IPV } \\
(\mathrm{n}=260)\end{array}$ & $\begin{array}{l}\text { Physical, no } \\
\text { sexual IPV } \\
(\mathrm{n}=225)\end{array}$ & $\begin{array}{c}\text { Psychological IPV, } \\
\text { no physical/sexual IPV } \\
\mathrm{n}=136\end{array}$ \\
\hline Poor general mental health & 16.1 & $2.7(2.0,3.8)$ & $1.9(1.3,2.9)$ & $1.7(1.0,2.7)$ \\
\hline Poor general physical health & 23.0 & $1.5(1.2,1.9)$ & $1.3(1.0,1.6)$ & $1.6(1.3,2.3)$ \\
\hline \multicolumn{5}{|l|}{ Substance use } \\
\hline Ever cigarette smoker & 36.4 & $1.6(1.3,1.9)$ & $1.6(1.3,1.9)$ & $1.5(1.1,1.8)$ \\
\hline Current cigarette smoker & 27.3 & $1.4(1.1,1.8)$ & $1.5(1.1,1.9)$ & $1.5(0.9,2.1)$ \\
\hline Alcohol abuse & 7.3 & $2.2(1.2,3.7)$ & $2.0(1.1,3.6)$ & $1.4(0.6,3.3)$ \\
\hline Drug abuse & 4.7 & $5.6(2.9,12.5)$ & $2.3(1.0,5.5)$ & $0.7(0.1,4.3)$ \\
\hline \multicolumn{5}{|l|}{ Anxiety and depression } \\
\hline PTSD symptoms ${ }^{\mathrm{b}}($ score $>30)$ & 30.6 & $2.5(1.4,4.0)$ & $1.7(1.0,2.8)$ & $1.3(0.5,3.3)$ \\
\hline Problem with anxiety & 28.9 & $1.9(1.7,2.4)$ & $1.7(1.4,2.2)$ & $1.5(1.2,2.1)$ \\
\hline State-Trait Anxiety score $>26$ & 10.3 & $4.5(2.9,7.7)$ & $2.8(1.6,5.0)$ & $2.8(1.5,5.6)$ \\
\hline Problem with depression & 31.5 & $12.5(7.1,20.0)$ & $11.1(6.3,20.0)$ & $9.1(5.6,16.7)$ \\
\hline Currently depressed & 25.2 & $2.5(2.0,3.3)$ & $1.8(1.3,2.4)$ & $2.0(1.4,2.8)$ \\
\hline \multicolumn{5}{|l|}{ Suicide ideation and actions } \\
\hline Ever considered suicide & 25.9 & $3.3(2.5,4.5)$ & $2.5(1.9,3.3)$ & $1.9(1.3,2.8)$ \\
\hline Ever attempted suicide & 11.8 & $4.8(3.0,7.7)$ & $3.6(2.2,5.9)$ & $2.1(1.1,4.2)$ \\
\hline
\end{tabular}

${ }^{a} R R$ adjusted for race, age, Medicaid insurance status.

${ }^{\mathrm{b}}$ Among 356 with PTSD event.

anxiety, depression, PTSD symptoms, and suicide ideation and actions than were abused women reporting lower social support and controlling for frequency of IPV (Table 3).

Finally, we looked at the sources of support from friends, family members, and male partners (Table 4). Women reporting that their friends were "always" emotionally supportive were significantly less likely to report poor mental health, anxiety, depression, and PTSD symptoms. Consistent emotional support from family was associated with a reduced risk of poor mental health, anxiety, and depression. Among those with a current male partner who was not the abusive part-

Table 3. Help Seeking, IPV Disclosure, and Social Support and Current Mental Health Outcomes among Abused Women $(n=621)$

\begin{tabular}{|c|c|c|c|c|}
\hline \multirow[b]{2}{*}{ Mental health $(\mathrm{MH})$ outcome } & \multirow[b]{2}{*}{$\begin{array}{c}\text { Prevalence of } \mathrm{MH} \\
\text { outcomes } \\
\text { among abused } \\
(\mathrm{n}=621)(\%)\end{array}$} & \multicolumn{3}{|c|}{ Adjusted RR $(95 \% \mathrm{CI})^{\mathrm{a}}$ estimate for $\mathrm{MH}$ outcome and } \\
\hline & & $\begin{array}{l}\text { Sought mental } \\
\text { health services } \\
\text { Yes vs. No } \\
95 / 167\end{array}$ & $\begin{array}{c}\text { Supportive response } \\
\text { to IPV disclosure } \\
\text { Yes vs. No } \\
132 / 489\end{array}$ & $\begin{array}{l}\text { Social support } \\
\text { High vs. low } \\
\quad 400 / 221\end{array}$ \\
\hline Poor overall mental health & 22.4 & $1.2(0.8,1.9)$ & $0.7(0.4,1.0)$ & $0.5(0.3,0.6)$ \\
\hline Poor overall physical health & 28.0 & $1.1(0.8,1.5)$ & $1.0(0.7,1.4)$ & $0.6(0.5,0.8)$ \\
\hline \multicolumn{5}{|l|}{ Substance use } \\
\hline Current cigarette smoker & 33.3 & $1.0(0.6,1.4)$ & $1.0(0.8,1.4)$ & $1.1(0.8,1.4)$ \\
\hline Alcohol abuse & 9.3 & $0.7(0.3,2.0)$ & $0.8(0.4,1.7)$ & $1.1(0.6,2.0)$ \\
\hline Drug abuse & 7.6 & $3.3(1.4,10.0)$ & $0.6(0.3,1.6)$ & $0.8(0.5,1.7)$ \\
\hline \multicolumn{5}{|l|}{ Anxiety and depression } \\
\hline PTSD symptoms (score >30) & 16.4 & $2.7(1.5,3.3)$ & $1.0(0.7,1.5)$ & $0.5(0.4,0.8)$ \\
\hline State-Trait Anxiety score $>26$ & 16.3 & $1.7(1.0,3.1)$ & $1.1(0.7,1.7)$ & $0.3(0.2,0.4)$ \\
\hline Currently depressed & 34.0 & $1.3(0.9,1.9)$ & $0.8(0.6,1.0)$ & $0.6(0.5,0.8)$ \\
\hline \multicolumn{5}{|l|}{ Suicide ideation and actions } \\
\hline Ever considered suicide & 36.8 & $1.3(0.9,1.7)$ & $0.6(0.4,0.8)$ & $0.8(0.6,0.9)$ \\
\hline Ever attempted suicide & 18.6 & $1.7(1.0,2.8)$ & $0.4(0.2,0.7)$ & $0.6(0.4,0.9)$ \\
\hline
\end{tabular}

${ }^{a} R R$ adjusted for race, age, Medicaid insurance status, IPV frequency, and severity.

${ }^{\mathrm{b}}$ Among those perceiving themselves to currently be in abusive relationship, $n=262$. 
ner (IPV in a past relationship only, $n=428$ ), consistent support from the current partner was significantly associated with a reduced risk of poor mental health, anxiety, and depression (Table 4).

Among abused women, higher levels of religiosity were not associated with a reduced risk of any of the mental health outcomes (data not shown) except alcohol abuse $(a R R=0.6,95 \% \mathrm{CI}$ $0.4,0.9$ ).

\section{DISCUSSION}

We found (1) different demographic correlates of IPV by type, (2) that these IPV types are associated with a range of adverse mental health outcomes, yet (3) if women experiencing IPV disclose the abuse and receive support to address the abuse, abused women will be at a significantly reduced risk of these same mental health outcomes.

This is one of the first large clinical studies to provide estimates of IPV by type, including physical, sexual, and psychological abuse as recommended by National Research Council ${ }^{44}$ and to further correlate IPV by type with adverse mental health consequences. To our knowledge, this is one of the first studies to assess the protective role of help seeking and social support on a range of mental health outcomes among abused women.

Our finding that abused women with higher levels of social support were less likely to attempt suicide is consistent with research reported by Kaslow et al., ${ }^{27}$ who found, in a case-control study of suicide attempters $(n=148)$ compared with nonattempters $(n=137)$, that the association between partner abuse and suicide attempts was moderated by social support. Our finding that sexual, physical, and psychological IPV are associated with a range of mental health outcomes is consistent with the abundant literature addressing this important public health issue. Romans-Clarkson et al. $^{45}$ found that IPV was associated with psychiatric morbidity, as was a lack of social networks. Others have shown that IPV is associated with poor perceived mental health, ${ }^{22,46-48}$ depression, ${ }^{15,49-51}$ anxiety, ${ }^{52,53}$ suicide ideation and actions, ${ }^{54-57}$ and PTSD. ${ }^{58-63}$

We posit that IPV affects women's mental health indirectly through increasing chronic psychological stress. ${ }^{64-66}$ Confiding the existence of a trauma has been shown to improve immune system functioning. ${ }^{67}$ Our data suggest that with respect to confiding about IPV, it is not enough just to talk. The recipient must be emotionally

Table 4. Emotional Support from Family, Friends, and Male Partners and Mental Health Outcomes among Abused Women $(n=621)$

\begin{tabular}{|c|c|c|c|}
\hline \multirow[b]{3}{*}{ Mental health $(\mathrm{MH})$ outcome } & \multicolumn{3}{|c|}{$\begin{array}{l}\text { Adjusted } \mathrm{RR}(95 \% \mathrm{CI})^{\mathrm{a}} \text { estimate for mental health outcome and } \\
\text { receiving consistent (vs. inconsistent or no) emotional support from }\end{array}$} \\
\hline & Friends & Family & $\begin{array}{l}\text { Current nonabusive } \\
\text { male partner }\end{array}$ \\
\hline & $251 / 370$ & $302 / 319$ & $174 / 254$ \\
\hline Poor overall mental health & $0.5(0.3,0.7)$ & $0.5(0.4,0.7)$ & $0.4(0.2,0.7)$ \\
\hline Poor overall physical health & $0.8(0.6,1.1)$ & $0.8(0.6,1.0)$ & $0.8(0.6,1.2)$ \\
\hline \multicolumn{4}{|l|}{ Substance use } \\
\hline Current cigarette smoker & $1.0(0.8,1.3)$ & $0.9(0.7,1.1)$ & $1.1(0.8,1.4)$ \\
\hline Alcohol abuse & $0.9(0.5,1.5)$ & $1.2(0.7,2.0)$ & $0.7(0.4,1.3)$ \\
\hline Drug abuse & $0.8(0.4,1.4)$ & $0.9(0.5,1.6)$ & $0.8(0.3,2.3)$ \\
\hline \multicolumn{4}{|l|}{ Anxiety and depression } \\
\hline PTSD symptoms (score >30) & $0.6(0.4,0.8)$ & $0.8(0.6,1.2)$ & $0.8(0.5,1.4)$ \\
\hline State-Trait Anxiety score $>26$ & $0.4(0.3,0.7)$ & $0.4(0.3,0.6)$ & $0.2(0.1,0.6)$ \\
\hline Currently depressed & $0.7(0.5,0.8)$ & $0.6(0.5,0.8)$ & $0.7(0.5,0.9)$ \\
\hline \multicolumn{4}{|l|}{ Suicide ideation and actions } \\
\hline Ever seriously considered suicide & $0.9(0.7,1.1)$ & $0.8(0.6,1.0)$ & $0.8(0.6,1.0)$ \\
\hline Ever attempted suicide & $0.9(0.6,1.3)$ & $0.7(0.5,1.0)$ & $0.7(0.4,1.1)$ \\
\hline
\end{tabular}

${ }^{a} R R$ adjusted for race, age, Medicaid insurance status, IPV frequency, and severity.

${ }^{\mathrm{b}}$ Among those experiencing past IPV $(n=428)$. 
supportive for there to be a positive impact on mental health. Thus, support appears central to improved coping with IPV. Although our findings are consistent with this hypothesized mechanism, we cannot rule out some alternative interpretations. One such interpretation is that the reports of lower social support and of more negative mental health status both reflect a third variable-negative affectivity or neuroticism. ${ }^{68} \mathrm{Al}-$ though negative affectivity could be part of the explanation of the relationship, the weight of the evidence supports a direct effect for traumatic experiences on mental and physical health outcomes. Partner abuse may be associated with alienation or estrangement from personal or social relations and reduced sense of worth, value, or self-esteem, both of which are mutually reinforcing. Increasing social support may counter both of these characteristics in ways that enhance psychological well-being while also enhancing coping skills and increasing the repertoire of assets with which a person constructs alternatives to the current abusive relationship.

Several limitations of these data deserve mention. Although we have attempted to create temporally correct mental health outcome measures and have used current mental health indicators, we still have cross-sectional data. We cannot establish the temporal sequence such that abuse occurred and was followed by consistent support, which then reduced the risk of the adverse mental health outcomes. These results are suggestive of a buffering effect of support on mental health, but they are not conclusive. We did not confirm diagnoses with existing medical records because many of the mental health outcomes of interest would not have been documented in a medical record (self-perceived mental and physical health, current depression, anxiety, PTSD symptoms, suicide ideation). Therefore, mental health outcome data may be misclassified. However, our finding that abused women who sought mental healthcare were more likely to have attempted suicide, have current PTSD symptoms, and abuse drugs does indicate that women are accurately reporting at least these adverse mental health indicators. It is possible that those who are able to find social support are those who would not develop adverse mental health outcomes. Our measure of past psychological or emotional abuse requires that women recognize and label themselves as being abused. This self-labeling can result in underestimating victimization.
The American Medical Association, ${ }^{69}$ American College of Obstetrics and Gynecology, ${ }^{70}$ and the American Academy of Family Practice ${ }^{71}$ recognize the impact of IPV on women's health and have called for efforts to address IPV. Healthy People 2010: National Health Promotion and Disease Prevention Objectives ${ }^{72}$ denotes prevention of violence as one of the 21 priority objectives for the nation. Healthy People 2000: Midcourse Review ${ }^{73}$ calls for the training of healthcare professionals to address the needs of victims of violence. Public health officials recommend that standard protocols be implemented in healthcare settings in the belief that early identification, supportive education, effective referral, and ongoing support can eventually reduce the prevalence of abusive injury by up to $75 \% .{ }^{74}$ These data suggest that abused woman who receive more support, either in general or in the context of abuse disclosure, may experience better mental health. Based on our findings, screening for all forms of IPV in combination with efforts to increase women's social network may result in better mental and, perhaps, physical health. Additional research is needed, however, to identify what abused women find to be supportive, in general or in the context of disclosure, and what they might recommend that healthcare providers do to support them in addressing abuse.

\section{CONCLUSIONS}

Our finding that social support reduces by almost one half the risk of adverse mental health outcomes among abused women has important implications for clinicians serving abused women. Clinicians may have a positive impact on their patients' health by being supportive when women disclose current or past abuse and by helping women draw on other means of support, such as therapists, support groups, friends, family, or current partners. Screening women for IPV (including physical assault, sexual assault, and psychological abuse) may help identify abuse earlier, perhaps before adverse mental health outcomes develop. These findings are also important for the general community. The results indicate that abused women who receive support from friends, family, or their current (nonabusive) partner are less likely to experience a range of adverse mental health consequences. More than half of the women in this clinical study reported phys- 
ical, sexual, or psychological IPV, and all three types have mental and physical health consequences. ${ }^{6}$ If this prevalence is reflective of other similar populations, it is likely that most persons will have contact with someone who has experienced IPV, whether they know it or not.

All of us who work in healthcare are participants in social networks made of complex arrangements of reciprocal, mutually supportive relationships to which we contribute and from which we benefit. This research makes a case for efforts to extend such networks to include women who have been excluded by virtue of abuse, shame, or controlling partners. To adequately address partner violence and its long-term sequelae of societal impacts for women and children, there must be an environment of support rather than blame for victims, accountability and early interventions for abusive partners, and a societal commitment to zero tolerance for partner abuse. These findings, however, also indicate that effective support need not be institutionalized or highly structured. Informal networks of support and spontaneous expressions of support and encouragement in both clinical practice and personal encounters may also prove effective in preventing further harm to women who have already suffered abuse.

\section{REFERENCES}

1. Freund KM, Bak SM, Blackhall L. Identifying domestic violence in primary care practice. J Gen Intern Med 1996;11:44.

2. Gin NE, Rucker L, Frayne S, Cygan R, Hubbell F. Prevalence of domestic violence among patients in three ambulatory care internal medicine clinics. J Gen Intern Med 1991;6:317.

3. Rath GD, Jarratt LG, Leonardson G. Rates of domestic violence against adult women by men partners. J Am Board Fam Pract 1989;2:227.

4. Bullock L, McFarlane J, Bateman LH, Miller V. The prevalence and characteristics of battered women in a primary care setting. Nurse Pract 1989;14:47, 50, 53.

5. Coker AL, Smith PH, McKeown RE, King MJ. Frequency and correlates of intimate partner violence by type: Physical, sexual, and psychological battering. Am J Public Health 2000;90:553.

6. Coker AL, Smith PH, Bethea L, King MR, McKeown RE. Physical health consequences of physical and psychological intimate partner violence. Arch Fam Med 2000;9:451.

7. Hathaway J, Silverman J, Aynalem G, Mucci L, Brooks D. Use of medical care, police assistance, and re- straining orders by women reporting intimate partner violence-Masssachusetts, 1996-1997. MMWR 2000;49:485.

8. Tjaden $\mathrm{P}$, Thoennes N. Prevalence, incidence, and consequences of violence against women: Findings from the National Violence Against Women Survey. Washington, DC: US Department of Justice, Office of Justice Programs, 1998.

9. Buelhler J, Dixon B, Toomey K. Lifetime and annual incidence of intimate partner violence and resulting injuries-Georgia, 1995. MMWR 1998;47:849.

10. Coker A, Oldendick R, Derrick C, Lumpkin J. Intimate partner violence among men and women-South Carolina, 1998. MMWR 2000;49:691.

11. Hale-Carlsson G, Hutton B, Fuhrman J, Morse D, McNutt L. Physical violence and injuries in intimate relationships-New York, Behavioral Risk Factor Surveillance System, 1994. MMWR 1996;1996:35.

12. Bensley L, Macdonald S, Van Eenwyk J, Simmons KW, Ruggles D. Prevalence of intimate partner violence and injuries-Washington, 1998. MMWR 2000; 49:589.

13. Smith $\mathrm{PH}$, Edwards $\mathrm{G}$. Battering among reproductive age women: Prevalence and health implications. Paper presented at 4th Annual Family Violence Conference, Durham, New Hampshire, 1997.

14. Abbott J, Johnson R, Koziol-McLain J, Lowenstein SR. Domestic violence against women. Incidence and prevalence in an emergency department population. JAMA 1995;273:1763.

15. Cascardi M, Langhinrichsen J, Vivian D. Marital aggression. Impact, injury, and health correlates for husbands and wives. Arch Intern Med 1992;152:1178.

16. Campbell J, Lewandowski LA. Mental and physical health effects of intimate partner violence on women and children. Psychiatr Clin North Am 1997;20:353.

17. Koss MP, Heslet L. Somatic consequences of violence against women. Arch Fam Med 1992;1:53.

18. Bergman B, Brismar B, Nordin C. Utilisation of medical care by abused women. Br Med J 1992;305:27.

19. Plichta S. The effects of woman abuse on health care utilization and health status: A literature review. Wom Health Issues 1992;2:154.

20. Plichta SB, Abraham C. Violence and gynecologic health in women 50 years old. Am J Obstet Gynecol 1996;174:903.

21. United States Department of Health and Human Services. Mental Health: A Report of the Surgeon General. Rockville, MD: U.S. Department of Health and Human Services, Substance Abuse and Mental Health Services Administration, Center for Mental Health Services, National Institutes of Health, National Institute of Mental Health, 1999.

22. Smith PH, Gittelman DK. Psychological consequences of battering. Implications for women's health and medical practice. NC Med J 1994;55:434.

23. Mitchell RE, Hodson CA. Coping with domestic violence: Social support and psychological health among battered women. Am J Community Psychol 1983; 11:629. 
24. Sullivan CM, Tan C, Basta J, Rumptz M, Davidson WSD. An advocacy intervention program for women with abusive partners: Initial evaluation. Am J Community Psychol 1992;20:309.

25. Thompson MP, Kaslow NJ, Kingree JB, et al. Partner violence, social support, and distress among innercity African American women. Am J Community Psychol 2000;28:127.

26. Arias I. Women's responses to physical and psychological abuse. In: Arriaga XB, Oskamp S, eds. Violence in intimate relationships. Thousand Oaks, CA: Sage, 1999:139.

27. Kaslow NJ, Thompson MP, Meadows LA, et al. Factors that mediate and moderate the link between partner abuse and suicidal behavior in African American women. J Consult Clin Psychol 1998;66:533.

28. Hudson W. Partner abuse scale: Physical. Tempe, AZ: Walmyr Publishing Co, 1992.

29. Attala JM, Hudson WW, McSweeney M. A partial validation of two short-form Partner Abuse Scales. Wom Health 1994;21:125.

30. McFarlane J, Parker B, Soeken K, Bullock L. Assessing for abuse during pregnancy. Severity and frequency of injuries and associated entry into prenatal care. JAMA 1992;267:3176.

31. Smith PH, Tessaro I, Earp JA. Women's experience with battering: A conceptualization from qualitative research. Wom Health Issues 1995;5:173.

32. Smith PH, Smith JB, Earp JA. Beyond the measurement trap: A reconstructed conceptualization and measurement of woman battering. Psychol Wom Q 1999;23:177.

33. Smith PH, Earp JA, DeVellis R. Development and validation of the Women's Experience with Battering (WEB) Scale. Wom Health 1995;1:273 .

34. O'Leary KD. Psychological abuse: A variable deserving critical attention in domestic violence. Violence Vict 1999;14:3.

35. Skinner HA. The Drug Abuse Screening Test. Addict Behav 1982;7:363.

36. Russell M, Bigler L. Screening for alcohol-related problems in an outpatient obstetric-gynecologic clinic. Am J Obstet Gynecol 1979;134:4.

37. Spielberger CD. Manual for the State-Trait Anxiety Inventory, rev ed. Palo Alto, CA: Consulting Psychologists Press, 1983.

38. Radloff LS. The CES-D Scale: A self-report depression scale for research in the general population. Appl Psychol Measurement 1977;1:385.

39. American Psychiatric Association: Diagnostic and statistical manual of mental disorders, 4th ed. DSM-IV. Washington, DC: American Psychiatric Association, 1994.

40. United States Bureau of the Census. National Health Interview Survey Field Representative's Manual. Washington, DC: US Public Health Service, 1994.

41. Sarason BR, Shearin EN, Pierce GR, et al. Interrelations of social support measures: Theoretical and practical implications. J Pers Soc Psychol 1987;52:813.
42. Gorsuch RL, Venable GD. Development of an "Age Universal" I-E Scale. J Sci Study Religion 1983;22:181.

43. Gorsuch RL, McPherson SE. Intrinsic/Extrinsic Measurement: I/E-revised and single-item scales. J Sci Study Religion 1989;28:348.

44. Crowell NA, Burgess AW. Understanding violence against women. Washington, DC: National Academy Press, 1996.

45. Romans-Clarkson SE, Walton VA, Herbison GP, Mullen PE. Psychiatric morbidity among women in urban and rural New Zealand: Psycho-social correlates. Br J Psychiatry 1990;156:84.

46. Mullen PE, Romans-Clarkson SE, Walton VA, Herbison GP. Impact of sexual and physical abuse on women's mental health. Lancet 1988;1:841.

47. Ratner PA. The incidence of wife abuse and mental health status in abused wives in Edmonton, Alberta. Can J Public Health 1993;84:246.

48. Fischbach RL, Herbert B. Domestic violence and mental health: Correlates and conundrums within and across cultures. Soc Sci Med 1997;45:1161.

49. Feldbau-Kohn S, Heyman RE, O'Leary KD. Major depressive disorder and depressive symptomatology as predictors of husband to wife physical aggression. Violence Vict 1998;13:347.

50. Sackett LA, Saunders DG. The impact of different forms of psychological abuse on battered women. Violence Vict 1999;14:105.

51. Vivian D, Malone J. Relationship factors and depressive symptomatology associated with mild and severe husband-to-wife physical aggression. Violence Vict 1997;12:3.

52. Grandin E, Lupri E, Brinkerhoff MB. Couple violence and psychological distress. Can J Public Health 1998; 89:43.

53. Hedin LW, Janson PO. The invisible wounds: The occurrence of psychological abuse and anxiety compared with previous experience of physical abuse during the childbearing year. J Psychosom Obstet Gynaecol 1999;20:136.

54. Kernic MA, Wolf ME, Holt VL. Rates and relative risk of hospital admission among women in violent intimate partner relationships. Am J Public Health 2000; 90:1416.

55. Roberts GL, Lawrence JM, O’Toole BI, Raphael B. Domestic violence in the emergency department: I. Two case-control studies of victims. Gen Hosp Psychiatry 1997;19:5.

56. Hendricks-Matthews MK. Survivors of abuse. Health care issues. Primary Care 1993;20:391.

57. Bergman B, Brismar B. Suicide attempts by battered wives. Acta Psychiatr Scand 1991;83:380.

58. Thompson MP, Kaslow NJ, Kingree JB, Puett R, Thompson NJ, Meadows L. Partner abuse and posttraumatic stress disorder as risk factors for suicide attempts in a sample of low-income, inner-city women. J Trauma Stress 1999;12:59.

59. Rollstin AO, Kern JM. Correlates of battered women's psychological distress: Severity of abuse and duration of the postabuse period. Psychol Rep 1998;82:387. 
60. Astin MC, Lawrence KJ, Foy DW. Posttraumatic stress disorder among battered women: Risk and resiliency factors. Violence Vict 1993;8:17.

61. Vitanza S, Vogel LC, Marshall LL. Distress and symptoms of posttraumatic stress disorder in abused women. Violence Vict 1995;10:23.

62. Saunders DG. Posttraumatic stress symptom profiles of battered women: A comparison of survivors in two settings. Violence Vict 1994;9:31.

63. Frank JB, Rodowski MF. Review of psychological issues in victims of domestic violence seen in emergency settings. Emerg Med Clin North Am 1999;17: 657, vii.

64. Cohen S, Line S, Manuck SB, Rabin BS, Heise ER, Kaplan JR. Chronic social stress, social status, and susceptibility to upper respiratory infections in nonhuman primates. Psychosom Med 1997;59:213.

65. Cohen S, Tyrrell DA, Smith AP. Psychological stress and susceptibility to the common cold. N Engl J Med 1991;325:606.

66. Cohen S, Doyle WJ, Skoner DP. Psychological stress, cytokine production, and severity of upper respiratory illness. Psychosom Med 1999;61:175.

67. Pennebaker JW, Kiecolt-Glaser JK, Glaser RD. Disclosure of traumas and immune function: Health implications for psychotherapy. J Consult Clin Psychol 1988;56:239.

68. Watson D, Pennebaker JW. Health complaints, stress, and distress: Beyond the role of negative affectivity. Psychol Rev 1989;96:234.

69. American Medical Association diagnostic and treatment guidelines on domestic violence. Arch Fam Med 1992;1:39.

70. American College of Obstetricians and Gynecologists. Domestic violence. ACOG technical bulletin No. 209. Int J Gynaecol Obstet 1995;51:161.

71. American Academy of Family Practice. Family violence. Am Fam Phys 1994;50:1636.

72. Department of Health and Human Services (DHHS). Healthy people 2010 objectives: Draft for public comment. Washington, DC: DHHS, 1998.

73. Department of Health and Human Services (DHHS). Healthy people 2000: National health promotion and disease prevention objectives, midcourse review. Washington, DC: DHHS, 1995.

74. Rosenberg ML, Fenley MA. Violence in America: A public health approach. New York, Oxford, 1991.

Address reprint requests to: Ann L. Coker, Ph.D. University of South Carolina Norman J. Arnold School of Public Health Department of Epidemiology and Biostatistics 800 Sumter Street HESC 207 Columbia SC 29208 
Copyright of Journal of Women's Health \& Gender-Based Medicine is the property of Mary Ann Liebert, Inc. and its content may not be copied or emailed to multiple sites or posted to a listserv without the copyright holder's express written permission. However, users may print, download, or email articles for individual use. 